\title{
A TEMÁTICA AMBIENTAL NO CURSO DE LICENCIATURA EM FÍSICA, NA MODALIDADE EAD, DA UNIVERSIDADE FEDERAL DO PIAUÍ
}

\author{
Clarice Maria de Sousa ${ }^{1}$ \\ Marcos Antonio Tavares Lira ${ }^{2}$ \\ Elinara Soares Barros de Sousa ${ }^{3}$
}

Resumo: $O$ presente trabalho analisa a abordagem ambiental no curso de Licenciatura em Física na modalidade de Educação a Distância $(E a D)$ da Universidade Federal do Piauí (UFPI). A pesquisa tem como objetivo geral abordar reflexões e discussões referentes ao tema meio ambiente. $\mathrm{Na}$ análise, três aspectos foram enfatizados: a questão ambiental, a formação de professores de Física e a grade curricular do curso. Para atingir o objetivo proposto, foi realizada pesquisa bibliográfica e aplicado questionário com o coordenador, docentes e discentes do curso como instrumento de coleta de dados. Com a pesquisa, concluiu-se que a abordagem ambiental no curso analisado é tratada com pouca ênfase e sugeriram-se possíveis soluções como forma de aprofundar a temática abordada.

Palavras-chave: Educação Ambiental; Física; Ensino a Distância.

\footnotetext{
1Universidade Federal do Piauí. E-mail: claricemariasousa@hotmail.com.

2 Universidade Federal do Piauí. E-mail: marcoslira@ufpi.edu.br.

3 Universidade Federal do Piauí. E-mail: elinarabarros@ufpi.edu.br.
} 


\section{Introdução}

O homem desenvolve suas características em função das condições existentes no meio em que se encontra, porém, este "meio" vem sofrendo grandes impactos e consequências ao longo dos anos devido ao seu comportamento. Em virtude disso, devem existir crescentes demandas por ações direcionadas às questões ambientais e os cursos da área de Ciências da Natureza possuem papel significativo nas discussões levantadas sobre o tema (FOGAÇA, 2013).

Diante desse contexto, analisa-se a abordagem ambiental no curso de Licenciatura em Física na modalidade $\mathrm{EaD}$ da Universidade Federal do Piauí. Atualmente, no estado do Piauí, o curso de Licenciatura em Física na modalidade EaD só é ofertado por esta Instituição de Ensino Superior (IES), razão pela qual se deu a escolha da mesma.

A pesquisa tem como objetivo geral analisar como a temática ambiental é abordada durante a formação dos docentes em Física. Para tanto, três aspectos foram enfatizados: as características do ensino a distância no Brasil; a grade curricular do curso de Licenciatura em Física, modalidade EaD; e a percepção dos discentes quanto à importância da temática ambiental para a formação.

Para atingir os objetivos propostos, o processo metodológico teve como base a pesquisa bibliográfica, revisando o conhecimento consolidado sobre o tema, visando adquirir o alicerce sobre o ensino de física e as temáticas relacionadas ao objeto da pesquisa.

Como instrumento de coleta de dados, foram aplicados questionários com coordenador, docentes que ministram ou ministraram disciplinas do eixo específico e discentes. Com os questionários, buscou-se analisar a percepção sobre a questão ambiental da gestão do curso e dos envolvidos no eixo ensino.

Em seguida, discutiram-se as principais ocorrências observadas nos dados obtidos, demonstrando consonância com as considerações das fontes bibliográficas consultadas para este estudo.

\section{Ensino a Distância no Brasil}

A educação a distância no Brasil foi reconhecida a partir do ensino por correspondência, já que era baseada em textos e exercícios conduzidos pelo correio. Na década de 80 , ela foi introduzida na universidade através do uso de vídeo cassete, televisão e rádio para os telecursos (MORAN, 2002). No entanto, foi no final da década de 90 que houve uma revolução no ensino brasileiro e a modalidade ganhou ainda mais destaque na legislação através da Lei o 9.394/96 de Diretrizes e Bases da Educação Nacional (LDB), que traz em seu art. 80 a proposta de incentivar "o desenvolvimento e a veiculação de programas de ensino a distância, em todos os níveis e modalidades de ensino, e de educação continuada". 
Fernandes (2010) afirma que até a promulgação da LDB, a educação a distância "foi vista, comumente, como um paliativo utilizado para atender, em determinados momentos, demandas específicas que se constituíam, geralmente, de estudantes excluídos do sistema regular de ensino".

Diante dessa evolução nota-se que a princípio a $\mathrm{EaD}$ foi percebida como forma de propagar a educação, oportunizando àqueles que não tinham acesso aos grandes centros de ensino. No entanto, além da propagação da educação, cabe destacar que a educação a distância é um processo educacional de grandes particularidades. Essa modalidade de ensino possui características próprias, principalmente pelos métodos de ensino que são utilizados, não para substituir o professor, mas como forma de complementar o processo ensino aprendizagem. Vale ainda frisar que a educação a distância já vinha sendo abordada na Lei no 5.692/1971, que fixa as diretrizes e bases do $1^{\circ}$ e $2^{\circ}$ graus, porém com pouca ênfase.

Atualmente, o ensino na modalidade a distância é o que mais cresce no Brasil, seja pelo avanço das tecnologias, pela facilidade desta modalidade ou pelas novas propostas da legislação e esse crescimento fica evidente. Segundo Maia e Mattar (2007, p xiii apud Vilaça, 2010, p. 90):

O crescimento do mercado de educação a distância $(E a D)$ é explosivo no Brasil e no Mundo. Dados estão disponíveis por toda parte: cresce exponencialmente o número de instituições que oferecem algum tipo de curso a distância, o número de cursos e disciplinas ofertados, de alunos matriculados, de professores que desenvolvem conteúdos e passam a ministrar aulas a distância, de empresas fornecedoras de serviços e insumos para o mercado, de artigos e publicações sobre EaD, crescem as tecnologias disponíveis, e assim por diante.

Nessa perspectiva, a visão de que a EaD seria um meio utilizado para expandir a educação é confirmada quando consideramos os dados gerais relacionados ao crescimento desta modalidade de ensino no país.

Em consonância com esse crescimento, a UFPI conta com uma estrutura exclusivamente voltada para a EaD. O Centro de Educação Aberta a Distância (CEAD) oferta 15 cursos e está presente em 41 municípios, distribuídos em 39 polos no estado do Piauí e dois na Bahia.

O curso de Licenciatura em Física, na modalidade EaD, é ofertado pela UFPI em quatro municípios: Piracuruca, Água Branca, São João do Piauí e Jaicós.

\section{Educação Ambiental e o Ensino de Física}

A Constituição Federal do Brasil destaca a importância do meio ambiente em seu capítulo VI, art. 225, ao enfatizar sobre o direito de todos a

revista brasileira educação ambiental 
um meio ambiente equilibrado e o dever tanto do poder público quanto da sociedade de defender e preservar o meio ambiente.

Com isso, a preocupação com a questão ambiental passou a ser destaque em leis ordinárias brasileiras, tal como ocorre no texto da LDB, que detalha os direitos e organiza os aspectos gerais do ensino e estabelece que na formação básica do cidadão seja garantida a compreensão do ambiente natural e social; que os currículos do ensino fundamental e do ensino médio englobem o conhecimento do mundo físico e natural; e que a educação superior amplifique o entendimento do ser humano e do meio em que vive. Baseado nisso, percebe-se que a educação ambiental é umas das principais ferramentas de orientação para a sensibilização da sociedade em relação às questões ambientais.

Em 1999, com a promulgação da Lei oㅜ 9.795, o Brasil se tornou o primeiro país da América Latina a possuir uma política nacional voltada para a educação ambiental. Esta Lei institui a Política Nacional de Educação Ambiental (PNEA) e estabelece critérios e normas para a educação ambiental, que é o "componente essencial e permanente da educação nacional, devendo estar presente, de forma articulada, em todos os níveis e modalidades do processo educativo, em caráter formal e não-formal".

A Lei prevê ainda o caráter transdisciplinar da educação ambiental em relação às instituições de ensino formal, sendo inserida nos conteúdos escolares e não abordada em uma disciplina específica. No entanto, faculta aos cursos de pós-graduação a criação de disciplina específica. Isso pode ser percebido no artigo 10, que defende que a educação ambiental seja:

[...] desenvolvida como uma prática educativa integrada, contínua e permanente em todos os níveis e modalidades do ensino formal. § 10 A educação ambiental não deve ser implantada como disciplina específica no currículo de ensino. § 2o Nos cursos de pós-graduação, extensão e nas áreas voltadas ao aspecto metodológico da educação ambiental, quando se fizer necessário, é facultada a criação de disciplina específica. (BRASIL, 1999).

A Lei ํo 9.795/1999 traz ainda em seu artigo 11 que a dimensão ambiental deve constar nos currículos de formação de professores, em todos os níveis e disciplinas e aborda em seu parágrafo único que:

Os professores em atividade devem receber formação complementar em suas áreas de atuação, com o propósito de atender adequadamente ao cumprimento dos princípios e objetivos da Política Nacional de Educação Ambiental. 
Com isso, destaca-se a necessidade de qualificação dos docentes para que possam fazer cumprir a legislação quanto à abordagem da temática ambiental na educação formal, sendo incluída de forma transversal no currículo escolar.

A Resolução CNE/CES no 2, de 15 de junho de 2012, que estabelece as Diretrizes Curriculares Nacionais para a Educação Ambiental, ratifica a Lei no 9.795/1999 quanto à transversalidade da temática na educação formal, como pode ser percebido no artigo 16 da resolução:

A inserção dos conhecimentos concernentes à Educação Ambiental nos currículos da Educação Básica e da Educação Superior pode ocorrer: I - pela transversalidade, mediante temas relacionados com o meio ambiente e a sustentabilidade socioambiental; II - como conteúdo dos componentes já constantes do currículo; III - pela combinação de transversalidade e de tratamento nos componentes curriculares.

Diante disso, percebe-se a importância da temática ambiental na formação de docentes em Física, levando em consideração que as ciências naturais estão relacionadas com tudo o que a natureza oferece e a Física em especial é uma das ciências mais fundamentais da natureza e que muito contribui para o desenvolvimento científico. Através dela é possível entender os processos que determinam o funcionamento do meio ambiente no planeta, sendo que a "percepção do saber físico como construção humana constitui-se condição necessária, mesmo que não suficiente, para que se promova a consciência de uma responsabilidade social e ética" (BRASIL, 2000, p. 27-28).

Destaca-se, ainda, a importância do ensino de Física para a preservação do meio ambiente e a necessidade de abordar a relevância das questões ambientais para melhorar não só a qualidade de vida, mas todo o ecossistema, não se limitando apenas como uma prática de conceitos e fórmulas. Por isso, é preciso que os docentes formados pelas IES possuam qualificação para tratar da temática em sala de aula.

Os Parâmetros Curriculares Nacionais (PCN) de Física para o ensino médio trazem um contexto essencial sobre a contribuição do ensino de Física para o tipo de cidadão que se pretende formar:

Espera-se que o ensino de Física, na escola média, contribua para a formação de uma cultura científica efetiva, que permita ao indivíduo a interpretação dos fatos, fenômenos e processos naturais, situando e dimensionando a interação do ser humano com a natureza como parte da própria natureza em transformação. Para tanto, é essencial que o conhecimento físico seja explicitado como um processo histórico, objeto de 
contínua transformação e associado às outras formas de expressão e produção humanas. É necessário também que essa cultura em Física inclua a compreensão do conjunto de equipamentos e procedimentos, técnicos ou tecnológicos, do cotidiano doméstico, social e profissional (BRASIL, 2000).

$\mathrm{Na}$ educação superior também não é diferente. Ao proporcionar esses conhecimentos, 0 aprendizado da Física promove a articulação entre sociedade e natureza, já que se trata de uma necessidade cada vez mais ostensiva. Baseando-se nessas perspectivas é possível perceber a importância que o ensino de Física de qualidade traz para a relação homem e natureza, introduzindo a questão ambiental desde o ensino básico até a formação profissional.

A educação ambiental é entendida como um direito de todos os cidadãos, capaz de articular o meio ambiente equilibrado a uma sadia qualidade de vida, além de proporcionar relação mais estreita entre processos educativos e a realidade. Por isso sua prática faz-se muito importante (REIS JÚNIOR, 2003).

Entretanto, mesmo com a implantação e avanço da legislação brasileira em desenvolver competências para preservar o meio ambiente a fim de garantir recursos ambientais às gerações futuras, somente as leis não são suficientes para sensibilizar e conscientizar a população sobre as questões ambientais.

\section{Metodologia da pesquisa}

A pesquisa é de natureza exploratória e cunho qualitativo descritivo. $O$ instrumento utilizado como pré-requisito para obtenção de dados foi questionário com perguntas objetivas e subjetivas, buscando obter informações sobre a percepção dos participantes sobre a temática ambiental.

Os questionários foram aplicados ao coordenador, seguindo um roteiro específico para o gestor; a cinco professores vinculados ao curso que ministram ou ministraram disciplinas específicas; e a dezenove discentes matriculados no Polo de Apoio Presencial de Água Branca-PI.

Os questionários foram realizados durante o mês de junho de 2016 com o intuito de perceber a visão do coordenador, professores e alunos quanto à abordagem dada à temática ambiental no curso de Licenciatura em Física na modalidade a distância da UFPI. Além disso, foi analisada a grade curricular através do Projeto Pedagógico Curso (PPC).

Logo após a conclusão da coleta de dados, foram realizadas discussões levando em consideração os dados obtidos e a bibliografia pesquisada. 


\section{Resultados e discussões}

A pesquisa foi realizada a partir da análise do PPC do curso de Licenciatura em Física, modalidade EaD, da UFPI. Além disso, foram utilizadas as respostas dos questionários aplicados aos docentes, discentes e ao coordenador, que correspondem aos eixos ensino e gestão da UFPI.

\section{Ensino}

\section{Projeto Pedagógico do Curso (PPC)}

O PPC é uma ferramenta utilizada como referência de todas as ações utilizadas no processo ensino/aprendizagem do curso. Segundo Barba (2011, p.84), em um currículo são consideradas as "construções históricas, culturais e sociais da realidade associadas ao conteúdo, à formação e à didática para a implementação dos mesmos". Ou seja, busca-se uma prática relacionando a realidade construída socialmente e o que a instituição espera de seu profissional.

Para Rodrigues (2014, p.204) o currículo é "um ambiente produzido pela interação dos homens com/no mundo, território de luta e contestação, constituído por relações de poder". Mais uma vez, o currículo é vinculado à realidade, onde a luta de poder é iniciada ainda durante a construção de um PPC, onde são estabelecidos os pontos importantes de uma profissão através da escolha de quais disciplinas serão ministradas, deixando de fora outras questões ao se excluir outras disciplinas da matriz curricular.

A UFPI estabelece em seu Plano de Desenvolvimento Institucional (PDI 2015-2019) a concepção de Projeto Pedagógico do Curso como:

[...] instrumento básico da gestão de ensino e como instrumento propulsor dos objetivos fundamentais do perfil profissional que se pretende construir. Consequentemente, sua elaboração exige uma reflexão acerca da concepção e das finalidades da educação e sua relação com a sociedade, bem como uma reflexão aprofundada sobre o tipo de indivíduo que se quer formar e de mundo que se quer construir.

Dessa forma, o currículo não se desvincula da realidade e percebe-se que a instituição se preocupa com o tipo de profissional que está formando. É a partir da elaboração de um PPC que se estabelece o caminho que será seguido na relação entre a educação formal e formação cidadã.

A resolução CNE/CES no 9, de 11 de março de 2002, que estabelece as Diretrizes Curriculares para os cursos de Bacharelado e Licenciatura em Física serve como uma orientação para a elaboração do PPC do referido curso.

O PPC do curso de Licenciatura em Física, na modalidade EaD, da UFPI traz como objetivo geral do curso além de formar professores para atuarem na educação básica e, principalmente, no Ensino Médio, "a 
competência, como concepção nuclear na orientação do curso; a coerência entre a formação oferecida e a prática esperada do futuro professor; e a pesquisa, focada nos processos de ensino e de aprendizagem".

Dentre os princípios curriculares que integram o curso, destaca-se a interdisciplinaridade, que embora pese a complexidade do conceito, pode ser interpretada como a abordagem de uma questão específica a partir do olhar de diversas disciplinas. Ainda nos princípios curriculares há um destaque para o currículo, sendo este que "assegura a formação para uma competente atuação profissional, assim as atividades desenvolvidas devem articular harmonicamente as dimensões: humana, técnica, político-social e ética".

Percebeu-se ainda a existência de uma disciplina optativa denominada Tópicos de Física Ambiental, com carga horária de 60h, que, segundo a ementa:

[...] visa discutir tópicos de Física de maneira interdisciplinar. Energia e a questão ambiental. Equilíbrio térmico da Terra e efeito estufa. Camada de ozônio. Radiação cósmica. Poluição e impactos ambientais no ar, água e solo. Matriz energética do Brasil (UFPI, 2014, p. 64).

Com isso, o PPC vai de encontro ao que sugere a Lei $n^{\circ}$ 9.795, de 1999, quanto à oferta de disciplina específica sobre a temática ambiental. Além disso, não é possível perceber nas ementas de todas as disciplinas a temática ambiental diretamente especificada, fazendo com que caiba a cada docente a iniciativa de introduzir a questão de forma transdisciplinar em suas aulas.

Diante da análise realizada, é possível compreender que a inclusão de uma disciplina optativa é utilizada como uma maneira de incluir precariamente a temática ambiental na formação dos docentes em Física. Ou seja, o PPC do curso não abrange a temática de forma transversal.

\section{Docentes}

Como forma de complementar as informações obtidas através da análise do PPC do curso, foram aplicados questionários com cinco professores que ministram ou ministraram disciplinas do eixo específico do curso de Licenciatura em Física na modalidade EaD. Tal escolha se deu pelo fato de se buscar perceber como a questão ambiental é vista e tratada pelos docentes das disciplinas voltadas para a formação desses profissionais. Para tanto, nos questionários foram abordadas questões que vão além do conteúdo ministrado em sala de aula.

O primeiro questionamento foi se a formação que é oferecida pela instituição onde eles trabalham é suficiente quanto à atuação no mercado de trabalho. Três responderam que concordam plenamente, ou seja, é suficiente. É necessário frisar que dentre estes, um deles também trabalha em outra IES que oferece o mesmo curso, porém em outra modalidade e a resposta pode estar relacionada ou não à outra instituição, já que através da pergunta não é Revbea, São Paulo, V. 12, № 4: 137-152, 2017. 
possível identificar a instituição e dois responderam que concordam parcialmente, isso quer dizer que estes concordam em partes, que somente a formação em si, não é totalmente suficiente. Vale destacar que ambos os professores só trabalham na IES pesquisada.

A segunda questão foi: Você trata sobre a temática ambiental em suas aulas? Como? Obtiveram-se as cinco respostas positivas. No entanto, apesar de todos responderem positivamente, quatro responderam que sim, sempre que possível tratam do tema, mas não aprofundaram suas justificativas, uma delas foi: "Sim. Demonstrando os efeitos físicos em algumas situações do dia a dia do aluno". E um docente informou que trata da questão ambiental na EaD especificamente, por possuir na grade curricular uma disciplina que aborda a temática, a resposta dada foi: "No Ensino básico (Ensino Médio), trato do assunto apenas superficialmente. Já na EaD, tratamos disso especificamente, pois na grade curricular há uma disciplina que trata dessa temática. Ela é ministrada com o auxílio de slides e vídeos". Diante das respostas apresentadas, verifica-se que a temática ambiental é abordada nas aulas, mesmo que de modo superficial, e mais aprofundada na disciplina específica.

A terceira questão buscou saber se estes docentes têm conhecimento da Lei 9.795/1999, que institui a PNEA. Quatro dos entrevistados responderam que possuem um conhecimento superficial, dentre estes um respondeu ter participado da elaboração do PPC e um respondeu simplesmente não ter conhecimento da Lei.

Já na quarta questão que trata da Resolução ํㅡ 2, de 15 de junho de 2012, na qual estabelece as Diretrizes Curriculares Nacionais para a Educação Ambiental, as respostas foram unânimes e os cinco docentes responderam ter conhecimento superficial da Resolução.

As respostas da terceira e quarta questões justificam a não abordagem da temática ambiental nas disciplinas que são ministradas pelos docentes, conforme demonstram as respostas obtidas no segundo questionamento. Com isso, percebe-se que não está sendo colocada em prática pelos docentes a abordagem da dimensão ambiental em todas as disciplinas na formação de professores, como estabelece a lei 9795/1999.

$\mathrm{O}$ quinto questionamento refere-se à relação professor de Física e Meio Ambiente, se essa ligação é importante. Mais uma vez os cinco professores responderam positivamente, que concordam plenamente que é importante essa relação e um dos fatos que pode estar associado a essas respostas é o de que a Física é uma das Ciências Naturais que investiga os fenômenos da natureza.

A sexta pergunta foi comum em todos os questionamentos (docentes, discentes e coordenador) e busca saber a percepção do conceito de desenvolvimento sustentável de todos os envolvidos na pesquisa. Analisando as respostas obtidas e considerando que este não possui uma definição concluída, nota-se que os docentes compreendem o desenvolvimento sustentável como um processo que integra aspectos ambientais, sociais, 
econômicos. Ter essa visão integradora é importante para o papel que eles desempenham na sociedade.

Cabe destacar ainda a resposta de dois docentes. Um respondeu: "desenvolvimento sustentável é dado pelo crescimento econômico de uma nação levando em consideração a preservação do meio ambiente como forma de garantir o bem-estar de gerações futuras". Outro professor respondeu: "é uma saída para o nosso crescimento econômico, tendo em vista que nossos recursos naturais estão se esgotando. Daqui a alguns poucos anos esse será um dos principais meios de crescimento econômico e social da população". Percebe-se nas respostas dos docentes uma visão limitada do desenvolvimento sustentável associado ao crescimento econômico, deixando de lado as dimensões social, ambiental, territorial e política, conforme estabelecidas por Sachs (2004).

A sétima questão também foi direcionada à gestão, bem como aos discentes, sobre o que está disposto na LDB (Que prevê que na formação básica do cidadão seja assegurada a compreensão do ambiente natural e social; que os currículos do Ensino Fundamental e do Médio devem abranger o conhecimento do mundo físico e natural; que a Educação Superior deve desenvolver o entendimento do ser humano e do meio em que vive; que a Educação tem, como uma de suas finalidades, a preparação para o exercício da cidadania) e todos dos docentes responderam que concordam plenamente que através da educação é possível formar cidadãos que compreendam 0 ambiente natural em que vivem.

Oitavo questionamento: em se tratando do tema transversal Meio Ambiente, como pode ser trabalhado a compreensão e valorização do desenvolvimento sustentável proposto pelas diretrizes curriculares na disciplina ministrada por você?

Alguns professores trouxeram respostas pouco aprofundadas, dizendo apenas que procuram orientar os alunos para preservarem o meio ambiente. Um professor afirmou: "Primeiramente, esse tema tem que deixar de ser transversal e passar a fazer parte do currículo como disciplina efetiva e não tratado esporadicamente em algumas poucas disciplinas e apenas na semana do meio ambiente". Esse mesmo docente ainda afirmou que o tema desenvolvimento sustentável tem urgência de ser tradado e pode ser trabalhado através de vídeos, textos e outros meios necessários à compreensão do discente.

Diante dessa resposta, percebe-se a importância da qualificação dos docentes quanto à dimensão ambiental, pois a visão apresentada ainda é fragmentada. A questão ambiental não pode ser vista dissociada de outras questões, como se a atuação do profissional não fosse afetar diretamente o meio ambiente. Por isso a necessidade de inclusão da temática de forma transdisciplinar e não disciplinar como defende o docente.

Destaca-se a resposta de outro professor, que trata da inclusão da 
quase todas as disciplinas do curso pode-se falar em energia. $O$ docente afirmou: "pode-se comentar a respeito das diversas formas de transformações de energias e procurar mostrar como podemos utilizá-la para nosso benefício e sempre destacar a importância das energias renováveis na garantia de preservação do meio ambiente".

É importante frisar nessa última resposta a existência de uma relação maior por parte da Física com o Meio Ambiente e que as disciplinas de física favorecem a abordagem ambiental. Porém, mesmo alguns docentes possuindo essa visão mais ampla e fazendo um paralelo com a segunda questão, percebe-se que isso não é posto em prática em sala de aula.

A partir das respostas dos docentes, percebe-se que a temática ambiental não é abordada de forma efetiva nas aulas e que isso é consequência da falta de qualificação na área ambiental que possa ampliar a visão do que é desenvolvimento sustentável e abordar a temática de forma transversal em suas disciplinas. É necessário maior aprofundamento acerca da temática ambiental, a fim de sensibilizar as pessoas quanto à necessidade de ter um ambiente sustentável e isso deve acontecer em todas as áreas do saber.

\section{Discentes}

A participação dos discentes nessa pesquisa é necessária para se ter a visão sobre a importância da temática ambiental para os futuros docentes em Física. Diante disso, foram aplicados questionários com dezenove alunos do Módulo VIII do Curso de Licenciatura em Física, modalidade EaD, matriculados no polo localizado na cidade de Água Branca.

A primeira questão: Você acha importante a abordagem do Aspecto Ambiental no Ensino de Física? Essa questão visa conhecer a percepção dos discentes quanto à relevância do tema no ensino de física. Dezoito alunos responderam que concordam plenamente, ou seja, eles acham que é importante fazer uma abordagem do aspecto ambiental no ensino de física e somente um discordou parcialmente. De acordo com os resultados obtidos é possível notar que os alunos possuem uma visão positiva quanto à importância dessa temática no ensino de física, o que pode contribuir para uma abordagem mais crítica do assunto, quando estiverem atuando como docentes.

O segundo questionamento foi: como você compreende os princípios e limites entre formação de professores de Física e Educação Ambiental? A essa questão dezoito alunos responderam positivamente, marcando que estão fortemente ligados e apenas um afirmou que esses temas são irrelevantes ou de pouca importância. Diante das respostas apresentadas percebe-se que a maioria dos entrevistados entendem que há uma relação entre professor de física/meio ambiente, o fato de a Física ser uma ciência que desvenda os fenômenos da natureza contribui para essa relação.

A terceira questão foi a seguinte: Qual sua visão hoje, como aluno, sobre a temática abordada e pelo fato de ser uma questão extremamente

revista brasileira educação ambiental 
importante e urgente para a vida? Embora a maioria dos discentes respondeu que concordam plenamente (um total de 15 alunos), houve divergência nas opiniões, em que dois responderam que concordam parcialmente, um mostrou indiferença e um preferiu não opinar. A maioria dos alunos entendem a temática ambiental como sendo importante e que tem uma ligação maior com a Física. No entanto, a questão ainda é abordada com pouca ênfase, como percebido através das respostas dos docentes entrevistados, que tratam do assunto de forma superficial.

A quarta questão trouxe como ponto importante a atuação desses alunos como profissionais: quando você for docente, acha necessário trabalhar a questão ambiental com seus discentes? Dezoito alunos responderam que é necessária a abordagem sobre o tema quando estiverem atuando como professores.

A quinta pergunta é de caráter subjetiva, foi comum a todos os entrevistados e refere- se ao conceito de desenvolvimento sustentável. Essa é uma questão extremamente importante, pois através dela é possível estabelecer a relação existente sobre a temática entre a exposição da gestão, professores e alunos com o conhecimento transmitido e/ou recebido. Analisando as definições dadas pelos discentes houve uma diversificação nas respostas, mas a maioria destacou a importância da preservação do meio ambiente fazendo uso racional, que garanta também o atendimento das necessidades atuais e futuras da sociedade.

A sexta questão busca saber a opinião dos discentes quanto ao que está disposto em uma das leis mais importantes que rege a educação brasileira, a LDB. O que propõe a legislação é que a temática ambiental seja introduzida desde a educação básica, no intuito de formar cidadãos capazes de compreender o ambiente natural e social. Embora nas respostas dezessete acreditem que seja positiva, houve um que discorda parcialmente e outro que não respondeu. Com isso, percebe-se que ainda existem pessoas que acham que a temática ambiental não deve ser tratada desde cedo, durante o início da formação do cidadão.

Diante das respostas obtidas nos questionários, percebe-se que os discentes têm uma visão positiva sobre a introdução da temática ambiental em suas vidas como profissionais. No entanto, é necessário buscar mais conhecimento sobre o assunto para que possa ser repassado de forma interdisciplinar, ajudando a formar cidadãos críticos.

\section{Gestão}

Sobre o eixo gestão, a análise foi efetuada a partir da percepção do coordenador do curso de Física na modalidade EaD da UFPI, somente em relação às questões específicas do cargo de coordenador e integrante da comissão de elaboração do PPC. O primeiro questionamento realizado foi: Atualmente, existe na grade curricular do curso alguma disciplina que trate da questão ambiental? A resposta dada foi sim e pode ser comprovada através da 
análise feita do PPC, onde consta a disciplina optativa denominada Tópicos de Física Ambiental, como mencionado anteriormente.

A segunda pergunta buscou verificar quanto ao conhecimento em relação a Lei 9.795/1999, que institui a Política Nacional de Educação Ambiental. O entrevistado respondeu não ter conhecimento da Lei.

Terceira questão: Tem conhecimento da Resolução ํㅡ 2, de 15 de junho de 2012, na qual estabelece as Diretrizes Curriculares Nacionais para a Educação Ambiental? A respostada dada foi sim, superficialmente. Isso quer dizer que ele não tem um conhecimento aprofundado da mesma. As respostas dadas à segunda e terceira questão demonstram a fragilidade da gestão do curso quanto à cobrança do cumprimento das normas estabelecidas, o que acaba fazendo com que a gestão não solicite aos docentes que abordem a temática em suas aulas.

Quarta questão: caso tenha conhecimento das legislações supracitadas, você acha que o perfil do profissional (Licenciado em Física) formado por esta universidade está de acordo com o que estabelece o Plano Nacional de Educação Ambiental e as diretrizes curriculares nacionais para a educação ambiental? Embora o entrevistado tenha respondido não ter conhecimento da PNEA e tenha afirmado conhecer superficialmente a Resolução que estabelece as diretrizes curriculares nacionais para a educação ambiental, seria possível responder o questionamento, porém o mesmo não respondeu.

Questão cinco: você acha importante a relação professor de Física e Meio Ambiente? A resposta apresentada foi positiva, marcando que concorda plenamente. Isso é entendido que há uma relação entre professor de física/meio ambiente, o que facilita aos docentes a abordagem da temática em suas aulas.

A sexta pergunta foi comum a todos os entrevistados e trata-se da definição de desenvolvimento sustentável: como você percebe o conceito de desenvolvimento sustentável? O gestor respondeu que entende que a "sustentabilidade está associada a maneira como a sociedade faz uso dos recursos naturais a fim de garantir futuro para as próximas gerações". $\mathrm{Na}$ resposta do coordenador, assim como pode ser percebido nas respostas dadas pelos docentes, há uma limitação da temática à questão dos recursos naturais, não sendo feita uma relação com outras questões, ou seja, mais uma vez é apresentada uma visão fragmentada da temática ambiental. É importante destacar que este é um termo que possui um conceito sistêmico, já que está relacionado com a continuidade nos aspectos ambientais, sociais, econômicos e culturais de toda a sociedade.

A questão sete pretende saber a opinião quanto ao que está disposto na LDB (que prevê que na formação básica do cidadão seja assegurada a compreensão do ambiente natural e social; que os currículos do Ensino Fundamental e do Médio devem abranger o conhecimento do mundo físico e natural; que a Educação Superior deve desenvolver o entendimento do ser

revista brasileira educação ambiental 
humano e do meio em que vive; que a Educação tem, como uma de suas finalidades, a preparação para o exercício da cidadania). A resposta foi que "concorda plenamente". Com isso, o gestor vai ao encontro de que na formação do cidadão é imprescindível a compreensão do ambiente natural.

\section{Conclusões}

Diante das situações apresentadas é indispensável que a universidade crie condições mais concretas a fim de orientar a formação de seus futuros profissionais e oferecer-Ihes possibilidades de compreender a educação ambiental além de uma visão superficial, que seja capaz de trazer reflexões aprofundadas sobre a temática. As pesquisas bibliográficas e de campo confirmaram que durante a formação do profissional de Física, na modalidade $\mathrm{EaD}$, a temática ambiental é tratada esporadicamente.

Com os questionários respondidos pelos docentes, constatou-se que não há uma preocupação dos professores em formar criticamente os alunos sobre o assunto. Embora na maioria dos assuntos de Física seja possível falar sobre meio ambiente, como destacou um dos professores participantes dessa pesquisa, isso não é o que de fato ocorre, já que os docentes não enfatizam a temática nessas disciplinas.

Mesmo tendo uma disciplina específica na grade curricular do curso, que traz em sua ementa preocupação quanto à questão ambiental, conforme análise feita no PPC, essa também não é uma realidade vivenciada na prática.

Vale ressaltar que a Lei oㅜ 9.795/1999 dispõe em seus princípios básicos a educação ambiental a partir de uma perspectiva transdisciplinar, ou seja, deve ser entendida entre, além e através das disciplinas, mas que não estabelece obrigatoriedade de implantar disciplina específica nos cursos de educação básica e superior.

Nesse sentido, percebe-se a razão pela qual o tema meio ambiente é tido como transversal, pois lida com atitudes e valores e deve ser tratado nas mais diversas áreas do conhecimento, como disposto nos PCNs de Meio Ambiente e Saúde:

Os conteúdos de Meio Ambiente serão integrados ao currículo através da transversalidade, pois serão tratados nas diversas áreas do conhecimento, de modo a impregnar toda a prática educativa e, ao mesmo tempo, criar uma visão global e abrangente da questão ambiental (BRASIL, 1997, p.36).

Diante desse contexto, faz-se necessário que haja uma nova visão em relação às questões ambientais, que os profissionais em formação tratem a temática de forma mais centrada e a que a universidade também faça sua parte e ofereça aos docentes em atividade formação complementar em suas áreas de atuação, como é proposto na legislação.

Quanto à legislação pertinente ao meio ambiente, nota-se pouco 
conhecimento tanto por parte da gestão quanto dos docentes e que o estabelecido pelas Diretrizes Curriculares Nacionais para a Educação Ambiental ainda não foi concretizado, uma vez que não são enfatizados como deveriam em sala de aula. Além disso, cabe destacar que somente as leis são insuficientes para fortificar a consciência crítica sobre as questões ambientais.

Sobre o conceito de desenvolvimento sustentável foi possível estabelecer a relação existente sobre a temática entre a exposição da gestão, professores e alunos com o conhecimento transmitido e/ou recebido. E o que prevalece é o senso comum, em que a maioria das respostas destacou a importância da preservação do meio ambiente fazendo uso racional e que garanta também as necessidades da sociedade e de gerações futuras. Poucas respostas traziam aprofundamento do tema, mas houve em algumas delas, uma visão um pouco além das demais, sendo incluídas também questões econômicas e sociais.

Diante disso, percebe-se que é necessário fazer um trabalho em conjunto, principalmente voltado para a qualificação de gestão e docentes sobre a temática ambiental, destacando a relevância do meio ambiente como forma de garantir uma sadia qualidade de vida, como propõe as diretrizes.

Diante dos fatos apresentados, acredita-se que os resultados servirão aos envolvidos na pesquisa como uma reflexão e estímulo sobre suas práticas educacionais, visto que os professores são os principais responsáveis por ensinar. Além disso, como forma de contribuição para o estudo é indispensável que os novos profissionais de Física, não só da modalidade a distância, construam uma visão crítica sobre o tema, capazes de irem além da sala de aula.

A temática abordada neste trabalho, apesar de já bastante conhecida na realidade escolar, é um campo extenso e aberto a novas contribuições como forma de aprofundar e aperfeiçoar os conhecimentos firmados, já que, apesar da contribuição no campo teórico, a prática cotidiana continua a ser inerte às possíveis soluções apresentadas. Assim sendo, a presente discussão e trabalhos futuros na área contribuirão para um campo fértil de modo a ampliar as ideias aqui contidas.

\section{Referências}

BARBA, C.H. Ambientalização curricular no ensino superior: o caso da Uuniversidade Federal de Rondônia - campus de porto velho. 2011. 310f. Tese (Doutorado em Educação Escolar) - Universidade Estadual Paulista, Faculdade de Ciências e Letras, Campus de Araraquara. Araraquara, 2011.

BRASIL. Constituição (1988). Constituição da República Federativa do Brasil. Brasília, DF. Senado Federal: Secretaria Especial de Editoração e Publicações, 2012. 103 p.

BRASIL. Lei №. 9.394, de 20 de dezembro de 1996. Lei de Diretrizes e Bases da Educação Nacional. Diário Oficial da União. Brasília, DF, 23 dez. 1996.

revista brasileira educação ambiental 
BRASIL. Ministério da Educação. Secretaria de Educação Fundamental. Parâmetros Curriculares Nacionais: Meio Ambiente, Saúde. Brasília: MEC, 1997.

BRASIL. Lei o 9795, de 27 de abril 1999. Dispõe sobre a educação ambiental, institui a Política Nacional de Educação Ambiental e dá outras providências. Diário Oficial da União. Brasília, DF, 28 abr. 1999.

BRASIL. Ministério da Educação. Secretaria de Educação Média e Tecnológica. Parâmetros Curriculares Nacionais (Ensino Médio): Ciências da Natureza, Matemática e suas Tecnologias. Brasília: MEC, 2000.

BRASIL. Conselho Nacional de Educação. Resolução CNE/CES 9, de 11 de março de 2002. Estabelece Diretrizes Curriculares Nacionais para os cursos de bacharelado e licenciatura em Física. Diário Oficial da União. Brasília, DF, 26 mar. 2002 - Seção 1 - p. 12.

BRASIL. Conselho Nacional de Educação. Resolução CNE/CES n. 2, de 15 de junho de 2012. Estabelece as Diretrizes Curriculares Nacionais para a Educação Ambiental. Diário Oficial da União. Brasília, DF, 18 jun. 2012 Seção 1 - p. 70.

FERNANDES, G.G. Introdução à educação a distância. Teresina, EDUFPI/UAPI, 2010.

FOGAÇA, S.D. Física x meio ambiente: a importância da física nos fenômenos Relacionados ao meio ambiente. Monografia de Especialização em Ensino de Ciências - Univers. Tecnológica Federal do Paraná. Medianeira, 2013. 32 f.

MORAN, J.M. A educação superior a distância no Brasil. Disponível em: $<$ http://www.eca.usp.br/prof/moran/site/textos/educacao online/eadsup.pdf>.

Acesso em 8 fev. 2017.

REIS JÚNIOR, A.M. A formação do professor e a educação ambiental. 2003. 194 f. Dissertação (Mestrado em Educação) - Universidade Estadual de Campinas, São Paulo.

RODRIGUES, A.R.S. Educação Ambiental em tempos de transição paradigmática: Entrelaçando Saberes "Disciplinados". Ciênc. Educ. Bauru, v. 20, n. 1, p. 195-206, 2014.

SACHS, I. Desenvolvimento: includente, sustentável, sustentado. Rio de Janeiro, Garamond, 2004.

UNIVERSIDADE FEDERAL DO PIAUÍ. PDI - Plano De Desenvolvimento Institucional 2015-2019. Resolução no 002/2015- Conselho Diretor/Conselho Universitário, de 15/07/2015. Disponível em: $<$ http://www.ufpi.br/images/cpa/PDI UFPI 2015 - 2019.pdf> Acesso. em: 05 jan. 2017.

UNIVERSIDADE FEDERAL DO PIAUÍ. Projeto Pedagógico do Curso de Licenciatura em Física- Modalidade a Distância. Teresina, 2014. 110p.

VILAÇA, M. L. C. Educação a Distância e Tecnologias: conceitos, termos e um pouco de história. Revista Magistro. Rio de Janeiro, v. 1, n. 2, p. 89-101, 2010.

Revbea, São Paulo, V. 12, № 4: 137-152, 2017. 